\title{
Correction to: Amino acid restriction alters survival mechanisms in pancreatic beta cells: possible role of the PI3K/Akt pathway
}

Bruna Lourençoni Alves ${ }^{1} \mathbb{D}$. Thiago dos Reis Araújo ${ }^{1}$. Dimitrius Santiago Passos Simões Fróes Guimarães ${ }^{1}$. Cláudio Cesar Zoppi ${ }^{1} \cdot$ Mariana Sarto Figueiredo $^{2} \cdot$ Everardo Magalhães Carneiro $^{1}$

Published online: 11 February 2022

(c) The Author(s), under exclusive licence to Springer-Verlag GmbH Germany 2022

\section{Correction to:}

European Journal of Nutrition (2021) 60:3947-3957

https://doi.org/10.1007/s00394-021-02568-2

The original version of this article unfortunately contained a mistake. In Fig. 4C and D, the images marked C (control) and $\mathrm{CW}$ (control pretreated with Wortmannin) are the same.

The corrected Fig. 4 is given in the following page.

The original article can be found online at https://doi.org/10.1007/ s00394-021-02568-2.

Everardo Magalhães Carneiro emc@unicamp.br

1 Obesity and Comorbidities Research Center (OCRC), Department of Structural and Functional Biology, Institute of Biology, University of Campinas (UNICAMP), R Carl Von Linnaeus, Campinas, SP CEP 13083-865, Brazil

2 Department of Nutrition and Dietetic, Faculty of Nutrition, Federal Fluminense University, Niteroi, RJ, Brazil 


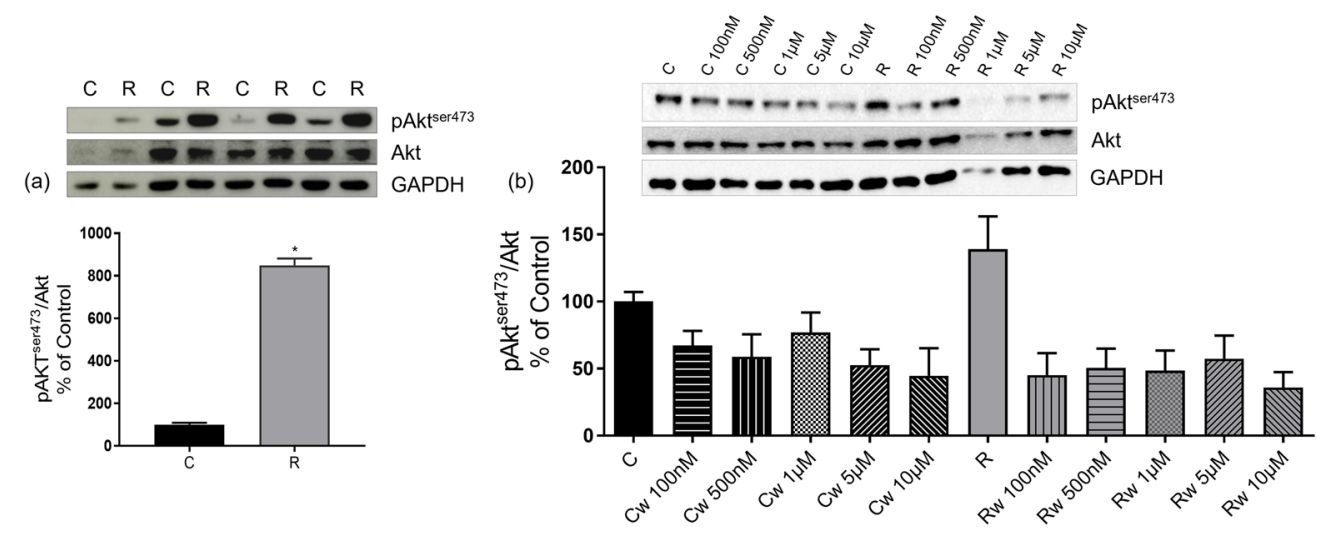

(c)

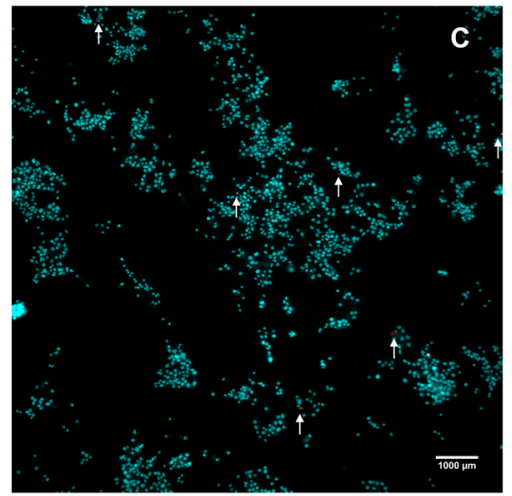

(e)

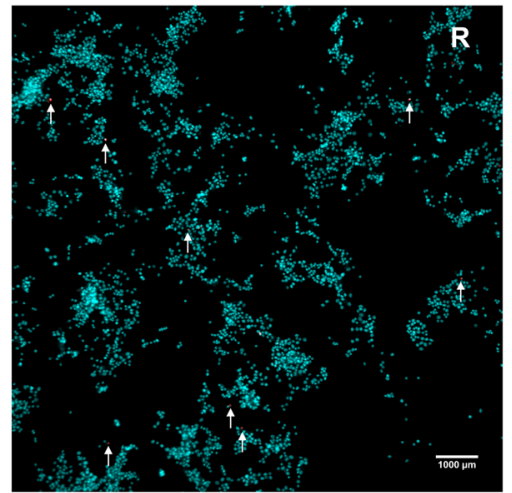

(d)

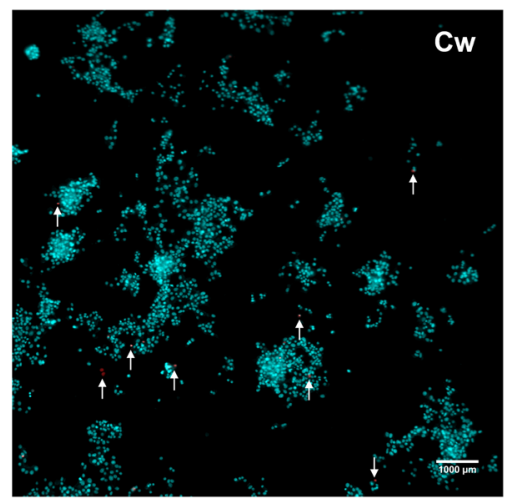

(f)

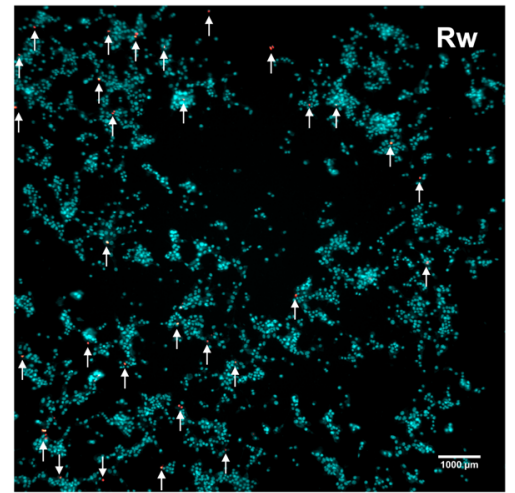

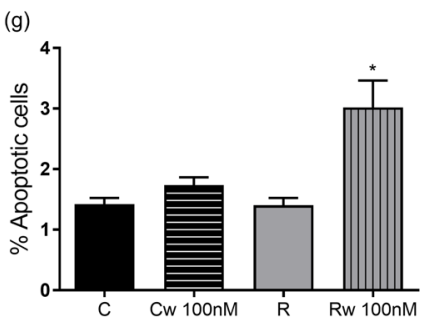
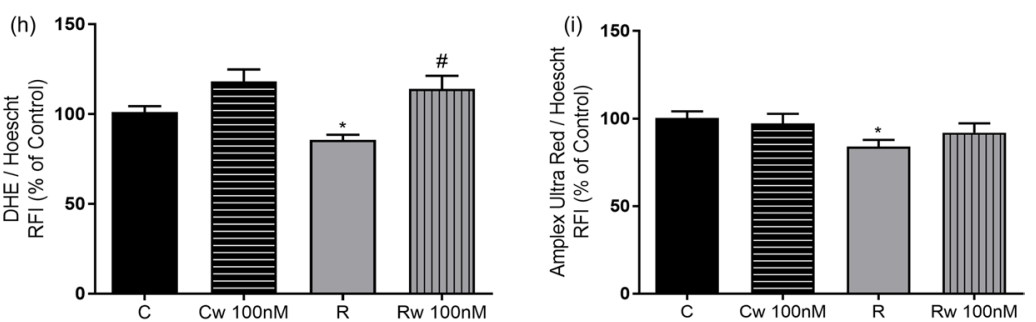

Fig. 4 Evaluation of Akt/PI3K pathway in cell viability and redox balance. Cells were submitted to the treatment with Wortmannin during $30 \mathrm{~min}$ before the $48 \mathrm{~h}$ of amino acid restriction. a Protein content of pAkt/Akt in basal situation and $\mathbf{b}$ after its inhibition by different concentrations of Wortmannin $(n=4-6)$. $\mathbf{c}-\mathbf{f}$ Representative images and percentage of apoptotic cells (g) costained with Hoechst 33,342 and propidium iodide, pictured and determined by the High Content
Imaging System in ImageXpress Micro Confocal $(n=5)$. h Superoxide content by DHE probe $(n=7)$. $\mathbf{i ~ H}_{2} \mathrm{O}_{2}$ production by Amplex probe $(n=7) . \mathrm{Cw}$ and $\mathrm{Rw}$ correspond to $\mathrm{C}$ and $\mathrm{R}$ pre-treated with Wortmannin. Data are mean \pm SEM and were submitted to Student $\mathrm{t}$ test for pAkt/Akt analyses, and to two-way ANOVA for Wortmannin analyses. $* p<0.05$ effect of amino acid restriction and ${ }^{\#} p<0.05$ effect of Wortmannin 